Intergenerational social mobility, smoking and smokeless tobacco (snus) use among adolescents during 2008-2017

\title{
Ruokolainen, Otto
}

2019-11

Ruokolainen, O , Ollila , H, Lahti , J \& Rahkonen , O 2019 , ' Intergenerational social mobility, smoking and smokeless tobacco (snus) use among adolescents during 2008-2017' , Addictive Behaviors , vol. 98 , 106022 . https://doi.org/10.1016/j.addbeh.2019.06.011

http://hdl.handle.net/10138/319695

https://doi.org/10.1016/j.addbeh.2019.06.011

unspecified

publishedVersion

Downloaded from Helda, University of Helsinki institutional repository.

This is an electronic reprint of the original article.

This reprint may differ from the original in pagination and typographic detail.

Please cite the original version. 


\title{
Intergenerational social mobility, smoking and smokeless tobacco (snus) use among adolescents during 2008-2017
}

\author{
Otto Ruokolainen ${ }^{\mathrm{a}, *}$, Hanna Ollila ${ }^{\mathrm{a}}$, Jouni Lahti ${ }^{\mathrm{b}}$, Ossi Rahkonen ${ }^{\mathrm{b}}$ \\ ${ }^{a}$ National Institute for Health and Welfare, Department of Public Health Solutions, Helsinki, Finland, Mannerheimintie 166, 00271, Po Box 30, Helsinki, Finland \\ ${ }^{\mathrm{b}}$ Department of Public Health, University of Helsinki, Tukholmankatu 8 B, 00014 University of Helsinki, Po Box 20, Helsinki, Finland
}

\section{H I G H L I G H T S}

- Youth smoking and snus use are strongly associated with the educational track.

- The risk for tobacco use is elevated in downward-mobile and stable low adolescents.

- Absolute differences in smoking decreased while relative differences increased.

- Absolute and relative differences in snus use increased among boys.

\section{A R T I C L E I N F O}

\section{Keywords:}

Smoking

Smokeless tobacco

Socioeconomic position

Social mobility

Inequalities, adolescent

\begin{abstract}
A B S T R A C T
Background: Socioeconomic differences in smoking and other tobacco use are prevalent in adolescents. Less is known about the association between intergenerational social mobility and tobacco use.

Methods: Five waves of national cross-sectional School Health Promotion Study during 2008-2017 in Finland were used, including non-academically and academically oriented adolescents (15-21 years, $\mathrm{N}=384,379)$. The adolescents' educational orientation was compared with the educational track of the parents as a proxy for intergenerational social mobility, which was used as the independent variable in regression models to examine the differences in daily smoking and daily snus use.

Results: Smoking declined in all mobility groups over time, but remained more prevalent among non-academically oriented adolescents among boys and girls. Daily snus use among boys increased over time in all mobility groups. Multiple adjusted models showed that upward mobility and downward mobility are differently associated with tobacco use, the latter increasing the probability of tobacco use compared with the stable high group (boys: smoking: $\mathrm{OR}=5.24,95 \%$ CI 5.02-5.46; snus use: OR $=1.57,95 \%$ CI $1.50-1.66$ ). In smoking, absolute socioeconomic differences between the mobility groups decreased over time while relative differences increased. In snus use, both absolute and relative differences increased.

Conclusions: Adolescent smoking and snus use associate strongly with the adolescent's educational track, irrespective of the social mobility class. Non-academically oriented adolescents have an increased risk of tobacco use. The academic and non-academic orientation should already be taken into account in tobacco use prevention in basic education.
\end{abstract}

\section{Introduction}

Smoking is a major preventable cause of morbidity and mortality. Smoking causes inequalities in health as those with a lower socioeconomic position (SEP) smoke more than those with a higher SEP (Ruokolainen, Heloma, Jousilahti, et al., 2019). Socioeconomic differences in smoking are already prevalent in adolescence, and while smoking prevalence has mainly decreased, these differences have persisted or increased (de Looze, ter Bogt, Hublet, et al., 2013; Doku, Koivusilta, Rainio, \& Rimpelä, 2010; Kuipers, Nagelhout, Willemsen, \& Kunst, 2014). It has been suggested that individual SEP is a stronger predictor of socioeconomic differences in smoking in adolescents than parental SEP (Doku et al., 2010; Kuntz \& Lampert, 2013; Paavola, Vartiainen, \& Haukkala, 2004). Academic orientation or educational

\footnotetext{
* Corresponding author.

E-mail addresses: otto.ruokolainen@thl.fi (O. Ruokolainen), hanna.ollila@thl.fi (H. Ollila), jouni.mm.lahti@helsinki.fi (J. Lahti),
} ossi.rahkonen@helsinki.fi (O. Rahkonen). 
track are common measures when examining inequalities in adolescent health (Hagquist, 2007).

In Finland, after nine years of compulsory education, two tracks are available: academically oriented general upper secondary education and work-life oriented vocational education and training. In 2016, 53\% of those who finished the comprehensive school continued their studies in general upper secondary school and $42 \%$ in vocational education and training (Statistics Finland, 2017). In 2017, 85\% of new university graduates had completed general upper secondary education, whereas $9 \%$ had completed vocational education (Vipunen, 2018). Studies show large differences in smoking between Finnish academically oriented and non-academically oriented adolescents (Tseveenjav, Pesonen, \& Virtanen, 2015). Other European studies confirm this gradient in adolescent smoking (Doku et al., 2010; Kuntz \& Lampert, 2013; Øverland, Tjora, Hetland, \& Aarø, 2010; Pedersen \& von Soest, 2017).

Less is known about the SEP differences in smoking in the context of intergenerational social mobility, especially over time. Intergenerational social mobility refers to a situation where adolescents are on a different educational track than that of their parents. Two studies from Finland imply that upward (downward) mobility is associated with smaller (greater) likelihood of smoking among adolescents (Karvonen, Rimpelä, \& Rimpelä, 1999; Paavola et al., 2004). A Swedish study suggests that smoking predicts downward social mobility, whereas not smoking predicts upward mobility (Novak, Ahlgren, \& Hammarstrom, 2012). The likelihood of smoking among stable low and downward-mobile adolescents was greater in comparison with the stable high or upward-mobile German adolescents (Kuntz \& Lampert, 2013).

In Finland, snus (Swedish type moist snuff) use has increased in recent years (National Institute for Health and Welfare, 2018). Selling snus is prohibited in all EU-countries except Sweden, and as Finland shares a border with Sweden, importing snus to Finland for personal use is relatively common. Only a few studies considering snus use and adolescent SEP have been published. They indicate that differences in snus use according to adolescent SEP seem non-existent or reversed compared with smoking (Mattila, Raisamo, Pihlajamäki, Mantysaari, \& Rimpelä, 2012; Øverland et al., 2010; Tseveenjav et al., 2015). One study in Norway examined tobacco use, including snus use, and SEP during 2004-2007 and found no changes in these associations (Øverland et al., 2010). To our knowledge there are no studies about the association of snus use with intergenerational social mobility.

\subsection{The research questions}

The aim of this study was to examine the association between intergenerational social mobility and tobacco use among adolescents during 2008-2017. Our two research questions are as follows: Have daily smoking and snus use changed among social mobility groups during 2008-2017? Do parental smoking and unemployment, as well as the price of tobacco, explain the differences in smoking and snus use between social mobility groups?

\section{Materials and methods}

\subsection{Participants and procedures}

Data came from five waves (2008/2009, 2010/2011, 2013, 2015, 2017) of the national repeated cross-sectional School Health Promotion Study. After excluding missing observations (4\%), the overall number of participants was $\mathrm{N}=384,379$ (if not otherwise noted, missing observations were omitted). The data is collected from first and second year students in general upper secondary schools and students in vocational schools (age distribution: 15-21 years old). Before the year 2013, the study was implemented in Southern, Eastern and Northern Finland in even-numbered years and in Western and Central Finland in odd-numbered years. Odd- and even-numbered years were pooled for national estimates. From 2013 onwards, the study has been carried out nationwide every second year. The survey is conducted as an anonymous and voluntary classroom questionnaire that was available in Finnish, Swedish, English and Russian. The study protocol was accepted by the Institutional Review Board of the National Institute for Health and Welfare.

All Finnish schools providing youth education are invited to participate in the survey. The estimated coverage rate of the survey is based on student enrolment statistics from Statistics Finland. The coverage declined throughout the years for upper secondary school students (74\% during 2008-2009, 55\% in 2017). The lower coverage in 2015-2017 is mostly due to technical problems in the electronic questionnaire, introduced to the survey in 2015. The technical problems occurred randomly and the corresponding research team has estimated that the data was not skewed and comparability to earlier study waves was obtained on the national level (personal communication). Distributions of the demographic variables (gender, age, maternal/paternal education) 2013 onward supports this (not shown). For vocational schools, the coverage cannot be reliably estimated due to inexact student enrolment statistics.

\subsection{Variables}

\subsubsection{Outcome variables}

A daily smoking index was formed of two questions: 'How many cigarettes, pipefuls and cigars have you smoked altogether?' ('None', 'Just one', 'About 2-50', 'More than 50') and 'Which of the following alternatives best describes your current smoking habits?' ('I smoke once a day or more often', 'I smoke once a week or more often, but not every day', 'I smoke less often than once a week', 'I have quit smoking [temporarily or permanently]'). Those, who had smoked at least two cigarettes and reported smoking daily, were classified as daily smokers. Respondents who did not answer both of the questions were omitted ( $n=442$ of the final data). Snus use was assessed with a question 'Have you ever used snus?' with answer options 'Not at all', 'I have tried it once or twice', 'I use it now and then', 'I use it every day' (classified as daily users of snus), and 'I used to use it, but I quit'. As daily snus use among the girls in the study was almost nonexistent $(0.4 \%$ in 2008-2017), it was only further examined among boys.

\subsubsection{Main predictor variable}

The school type of the participants was used as a proxy for individual-level SEP. General upper secondary education is interpreted as academically oriented education and vocational education is interpreted as non-academically oriented education. The respondent's SEP was used together with parental education level to compute the variable describing potential intergenerational social mobility. Maternal and paternal education was dichotomised as high education (university or other tertiary education) or other education. Following the dominance approach (Erikson, 2006), a variable for parental education was categorised ('At least one parent has a high level of education', 'Both parents have a lower level of education'). Academically oriented adolescents with at least one highly educated parent were classified as stable high, and adolescents in academically oriented education with parents with a lower level of education were classified as upward-mobile. Participants following a non-academic school track with parents with a lower level of education were classified as stable low, and nonacademically oriented adolescents with highly educated parents were classified as downward-mobile.

\subsubsection{Covariates}

A continuous age variable from 15 to 21 was used. The missing observations ( $n=7706$ of the final data) were replaced by the mean age according to the school level, gender and the study year. Since the nationwide data collection was carried out in two subsequent years in 2008-2009 and in 2010-2011, these years were pooled together. Thus, 
the study variable consisted of five time points (2008-2009, 2010-2011, 2013, 2015, 2017). The smoking status of the mother and father was reported by the adolescent (as either 'He or she is a nonsmoker', 'He or she has smoked', 'He or she is a current smoker', 'I do not know'). The missing observations for the variable ( $n=11,708$ of the final data) were classified as 'Did not report'. A dichotomous variable describing the unemployment of the parents (past 12 months) was used ('Not unemployed', 'At least one parent is unemployed').

The real price index of cigarettes and snus price index during 2008-2017 were used in multiple adjusted models. These data were obtained from Statistics Finland and Statistics Sweden. The mean value of the annual averages of two subsequent years was used to match the snus/cigarette price index with the corresponding year variable. As the snus that is being used in Finland comes exclusively from Sweden, the price of snus and its changes in Sweden were used.

\subsection{Statistical analyses}

Cross-tabulations and Pearson's $\chi^{2}$-tests were used to observe the differences in daily smoking among demographic variables and over time in the social mobility groups. Both absolute and relative differences in tobacco use were calculated to support the interpretation of whether the differences between mobility groups changed over time (Hoebel, Kuntz, Kroll, et al., 2018; Homma, Saewyc, \& Zumbo, 2016). Absolute changes were calculated as percentage point changes in tobacco use within a social mobility group, while relative changes were calculated as prevalence ratios between the social mobility groups (group with the highest prevalence in a given study year/group with the lowest prevalence in a given study year).

After the descriptive analyses, logistic regression was used to test the statistical significance of the trend for the prevalence of daily smoking and daily snus use, applying the method used in earlier studies (Hoebel et al., 2018). For this analysis, study year as a continuous variable was used as the independent variable (range $[0,1]$ ): 2008-2009 was coded as $0.000,2010-2011$ as $0.143,2013$ as 0.429 , 2015 as 0.714 , and 2017 as 1.000 . The analyses were stratified by gender and social mobility class. Multiple adjusted associations of smoking and snus use with intergenerational mobility were further analysed with binary logistic regression (Tables 2 and 3). Model 1 included social mobility, age and study year (encoded from 1 to 5 ). The smoking status of parents and parental unemployment were added to Model 2. The real price index for cigarettes (only for daily smoking) and the snus price index (only for daily snus use) were added to the final model (Model 3). In the Model 4, interaction term between study year and social mobility class was introduced to test whether smoking and snus use differed between the social mobility classes according to time. In all analyses, a 95\% confidence level was applied. The software used was StataSE 15.1.

\section{Results}

\subsection{Descriptive analyses}

Daily smoking was more prevalent among adolescents in vocational schools and those in the stable low and downward-mobile groups (Table 1). The offspring of less educated parents, parents with recent unemployment, and parents who smoke, smoked more often than their counterparts. Among all demographic variables, smoking was more prevalent in the beginning than at the end of the study period.

Daily smoking in boys and girls was more prevalent among stable low and downward-mobile adolescents compared with the stable high and upward-mobile groups (Fig. 1). Smoking declined in all subgroups over time among both genders (trend for all subgroups, $\mathrm{p}<.001$ ). Daily snus use prevalence was around $4 \%$ in 2008-2009, and was the most common among downward-mobile boys for the whole study period (Fig. 2). Snus use increased over time among all subgroups (p <.001 for the trend). During 2015-2017, the increase only continued in the non-academic oriented groups. Absolute changes in smoking prevalence over the study period showed a steeper decline in the downward-mobile group ( $22 \%$ for boys, $16 \%$ for girls), indicating a decrease in absolute differences in smoking between socioeconomic groups. However, the relative differences between social mobility groups increased during this time; for boys the prevalence ratio increased from 3.95 to 8.94, and for girls from 4.05 to 8.68. In snus use among boys, socioeconomic differences widened as the absolute increase among the downward-mobile group was greater (14\%) than the increase in other groups. The relative differences in snus use between social mobility groups also increased (prevalence ratio in 2008-2009 1.80 vs. 3.02 in 2017).

\subsection{Multiple adjusted analyses}

Table 2 shows the association of daily smoking by intergenerational social mobility groups when several covariates are added in the model. Smoking was more likely among the stable low and downward-mobile adolescents when compared with the stable high adolescents in each model. Smoking was less likely among the upward-mobile adolescents when compared with the stable high adolescents (Model 3). The findings were parallel among boys and girls. The estimates for intergenerational mobility groups among boys showed similar but weaker associations with daily snus use than with daily smoking (Table 3). Compared with the stable high group, adolescents in the upward-mobile group were less likely to use snus, but adolescents in the downward-mobile group were more likely to use snus (Model 3).

Statistically significant interactions between intergenerational social mobility and the study year indicated that the change over time in smoking and snus use was not the same for the different social mobility classes (Tables 2 and 3, Model 4). Analyses stratified by study year (Supplementary Table 1, 2 and 3; the price variables omitted from the models because of collinearity) showed, however, similar associations to the pooled analysis (Model 3).

\section{Discussion}

We studied adolescent SEP and tobacco use in the context of intergenerational social mobility in Finland during 2008-2017. Our main result is that daily smoking among youth differentiates strongly with the school type, irrespective of social mobility. That is, adolescents in vocational schools are more likely to smoke than adolescents on a more academic-oriented educational track. Our results show a decline in smoking prevalence and in absolute socioeconomic differences in smoking. Relative differences between socioeconomic groups in smoking still increased. Among boys, an increasing trend for snus use was detected, especially among non-academically oriented groups, indicating increasing absolute and relative socioeconomic differences in snus use. Parental background and the price of tobacco had a modest effect on the examined associations.

The stable low and downward-mobile groups were more likely to smoke and the upward-mobile group was less likely to smoke when compared with the stable high group. This supports earlier findings on the association between smoking and intergenerational social mobility (Karvonen et al., 1999; Kuntz \& Lampert, 2013; Novak et al., 2012). Adolescent smoking is more clearly associated to the school type than to the social mobility class. As parental SEP is included in the social mobility variable but absent from the school type variable, the adolescent's SEP might be more important than parental SEP when examining smoking (Paavola et al., 2004).

When several demographic factors were taken into account, the association between smoking and intergenerational mobility was attenuated but remained statistically significant. The observed difference in smoking between the stable high group and the upward-mobile group was reversed when the characteristics of the parents were taken into 
Table 1

Daily smoking by demographic variables in $2008-2017$ by study wave, $\mathrm{N}^{\mathrm{a}}$ and $\%^{\mathrm{b}}$.

\begin{tabular}{|c|c|c|c|c|c|c|c|c|c|c|c|c|c|}
\hline \multirow{3}{*}{ Age in years, mean (SD) } & \multicolumn{2}{|l|}{ 2008-2009 } & \multicolumn{2}{|l|}{$2010-2011$} & \multicolumn{2}{|l|}{2013} & \multicolumn{2}{|l|}{2015} & \multicolumn{2}{|l|}{2017} & \multicolumn{2}{|c|}{ Total (2008-2017) } & \multirow[t]{2}{*}{$\mathrm{p}^{\mathrm{c}}$} \\
\hline & $\begin{array}{l}17.6 \\
(0.82)\end{array}$ & 88,624 & $\begin{array}{l}17.6 \\
(0.84)\end{array}$ & 87,760 & $\begin{array}{l}17.7 \\
(0.86)\end{array}$ & 80,764 & $\begin{array}{l}17.6 \\
(0.90)\end{array}$ & 68,243 & $\begin{array}{l}17.2 \\
(1.16)\end{array}$ & 58,988 & $\begin{array}{l}17.6 \\
(0.89)\end{array}$ & 384,379 & \\
\hline & $\%$ & $\mathrm{~N}$ & $\%$ & $\mathrm{~N}$ & $\%$ & $\mathrm{~N}$ & $\%$ & $\mathrm{~N}$ & $\%$ & $\mathrm{~N}$ & $\%$ & $\mathrm{~N}$ & \\
\hline Daily smoking & 23.1 & 88,624 & 23.8 & 87,760 & 19.5 & 80,764 & 16.5 & 68,243 & 11.7 & 58,988 & 19.6 & 384,379 & \\
\hline Gender & & & & & & & & & & & & & $<0.001$ \\
\hline Boys & 24.8 & 42,559 & 25.9 & 42,695 & 20.6 & 38,423 & 16.8 & 32,068 & 12.3 & 28,505 & 20.9 & 184,250 & \\
\hline Girls & 21.4 & 46,065 & 21.8 & 45,065 & 18.5 & 42,341 & 16.2 & 36,175 & 11.2 & 30,483 & 18.41 & 200,129 & \\
\hline School type & & & & & & & & & & & & & $<0.001$ \\
\hline General & 10.2 & 49,361 & 10.6 & 47,595 & 8.1 & 47,412 & 5.6 & 38,262 & 3.3 & 33,468 & 7.9 & 216,098 & \\
\hline Vocational & 39.2 & 39,263 & 39.4 & 40,165 & 35.8 & 33,352 & 30.4 & 29,981 & 22.8 & 25,520 & 34.5 & 168,281 & \\
\hline Intergenerational social mobilty & & & & & & & & & & & & & $<0.001$ \\
\hline Stable high & 9.8 & 24,712 & 10.5 & 23,665 & 7.7 & 28,353 & 5.1 & 22,869 & 2.8 & 20,808 & 7.3 & 120,407 & \\
\hline Upward mobile & 10.6 & 24,649 & 10.7 & 23,930 & 8.7 & 19,059 & 6.4 & 15,393 & 4.0 & 12,660 & 8.7 & 95,691 & \\
\hline Downward mobile & 40.0 & 8659 & 40.1 & 9124 & 34.8 & 9571 & 28.8 & 8739 & 20.2 & 7959 & 33.1 & 44,051 & \\
\hline Stable low & 39.0 & 30,604 & 39.2 & 31,041 & 36.2 & 23,781 & 31.1 & 21,243 & 24.0 & 17,561 & 35.0 & 124,230 & \\
\hline Daily snus use ${ }^{\mathrm{d}}$ & & & & & & & & & & & & & $<0.001$ \\
\hline No & 24.7 & 40,838 & 26.0 & 40,414 & 20.7 & 35,099 & 16.3 & 28,519 & 11.6 & 24,940 & 20.8 & 169,810 & \\
\hline Yes & 27.5 & 1721 & 25.2 & 2281 & 20.2 & 3324 & 21.0 & 3549 & 17.3 & 3565 & 21.3 & 14,440 & \\
\hline Parental education & & & & & & & & & & & & & $<0.001$ \\
\hline Both parents less educated & 26.3 & 55,253 & 26.8 & 54,971 & 24.0 & 42,840 & 20.7 & 36,636 & 15.6 & 30,221 & 23.6 & 219,921 & \\
\hline $\begin{array}{l}\text { At least one parent highly } \\
\text { educated }\end{array}$ & 17.6 & 33,371 & 18.8 & 32,789 & 14.5 & 37,924 & 11.6 & 31,607 & 7.6 & 28,767 & 14.2 & 164,459 & \\
\hline Mother's education & & & & & & & & & & & & & $<0.001$ \\
\hline Other & 25.6 & 62,938 & 26.0 & 62,557 & 23.0 & 49,966 & 19.7 & 42,533 & 14.7 & 35,365 & 22.7 & 253,359 & \\
\hline High education & 16.8 & 25,686 & 18.4 & 25,203 & 14.0 & 30,798 & 11.2 & 25,710 & 7.3 & 23,623 & 13.6 & 131,020 & \\
\hline Father's education & & & & & & & & & & & & & $<0.001$ \\
\hline Other & 25.6 & 66,095 & 26.2 & 65,823 & 22.7 & 54,642 & 19.6 & 46,816 & 14.5 & 39,542 & 22.5 & 272,918 & \\
\hline High education & 15.7 & 22,529 & 16.7 & 21,937 & 12.9 & 26,122 & 9.9 & 21,427 & 6.2 & 19,446 & 12.5 & 111,461 & \\
\hline Mother's smoking status & & & & & & & & & & & & & $<0.001$ \\
\hline Has not smoked & 15.5 & 52,151 & 16.2 & 52,268 & 12.7 & 49,768 & 10.3 & 42,176 & 6.8 & 37,275 & 12.7 & 233,638 & \\
\hline Has quit & 30.0 & 14,914 & 31.6 & 14,936 & 27.3 & 13,674 & 22.7 & 11,879 & 17.6 & 8293 & 26.8 & 63,696 & \\
\hline Smokes & 39.6 & 16,967 & 41.2 & 16,349 & 37.1 & 13,560 & 33.0 & 11,270 & 26.5 & 8999 & 36.6 & 67,145 & \\
\hline Do not know & 23.0 & 3096 & 22.9 & 3155 & 20.2 & 2912 & 17.3 & 2543 & 12.7 & 1753 & 20.0 & 13,459 & \\
\hline Did not report & 27.6 & 1496 & 25.7 & 1052 & 13.4 & 850 & 16.0 & 375 & 12.2 & 2668 & 18.4 & 6441 & \\
\hline Father's smoking status & & & & & & & & & & & & & $<0.001$ \\
\hline Has not smoked & 13.9 & 38,245 & 14.3 & 38,678 & 11.3 & 37,356 & 8.8 & 31,563 & 5.9 & 29,315 & 11.2 & 175,157 & \\
\hline Has quit & 26.6 & 21,331 & 27.6 & 21,035 & 23.5 & 19,472 & 19.5 & 16,716 & 14.8 & 12,768 & 23.2 & 91,322 & \\
\hline Smokes & 34.9 & 22,724 & 36.5 & 21,978 & 31.9 & 18,585 & 28.4 & 15,420 & 21.8 & 12,115 & 31.8 & 90,822 & \\
\hline Do not know & 21.7 & 5014 & 23.4 & 5034 & 20.4 & 4609 & 18.6 & 4230 & 13.5 & 2924 & 20.1 & 21,811 & \\
\hline Did not report & 31.5 & 1310 & 31.5 & 1035 & 16.7 & 742 & 20.1 & 314 & 14.6 & 1866 & 22.8 & 5267 & \\
\hline Parental unemployment & & & & & & & & & & & & & $<0.001$ \\
\hline None & 21.2 & 64,847 & 21.8 & 60,532 & 17.5 & 57,530 & 14.3 & 45,799 & 10.3 & 40,314 & 17.7 & 269,022 & \\
\hline At least one & 28.1 & 23,777 & 28.2 & 27,228 & 24.7 & 23,234 & 21.0 & 22,444 & 14.9 & 18,674 & 23.9 & 115,357 & \\
\hline
\end{tabular}

a Number of respondents altogether.

b Proportion of daily smokers.

c P-value of Pearson chi-squared test between study year and demographic variable among daily smokers.

d Only among boys.

account. Additional analyses showed that parental smoking had a stronger influence on this association than parental unemployment, and the smoking of mothers and fathers influenced the association similarly (data not shown). The well-known association between parental and adolescent smoking (Rainio, Rimpelä, Luukkaala, \& Rimpelä, 2008; Vuolo, \& Staff, J., 2013) seems to also apply in the context of intergenerational social mobility, and appears to have an effect on smoking, especially among the upward-mobile adolescents. Surprisingly, the price of cigarettes had a negligible effect on the association between social mobility and smoking. In sensitivity analyses, the price of cigarettes was included in the model before parental factors, showing hardly any effect on the association (data not shown). This implies that
Boys

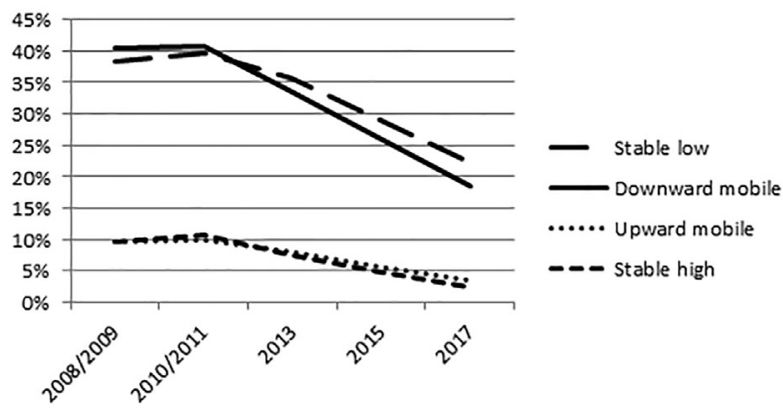

Girls

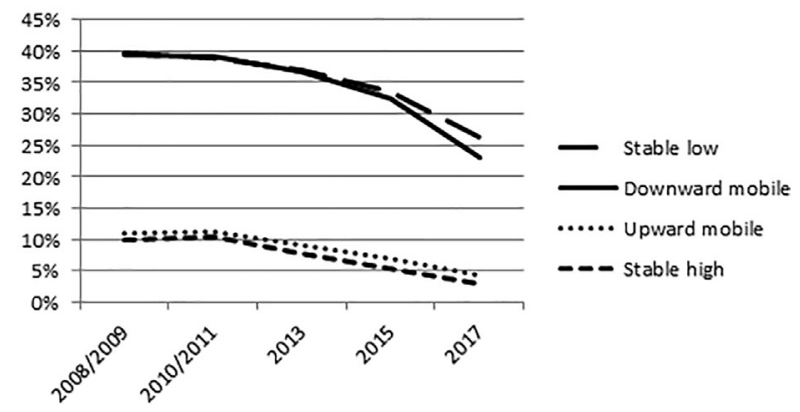

Fig. 1. Daily smoking among boys and girls by intergenerational social mobility, 2008-2017 (\%). 


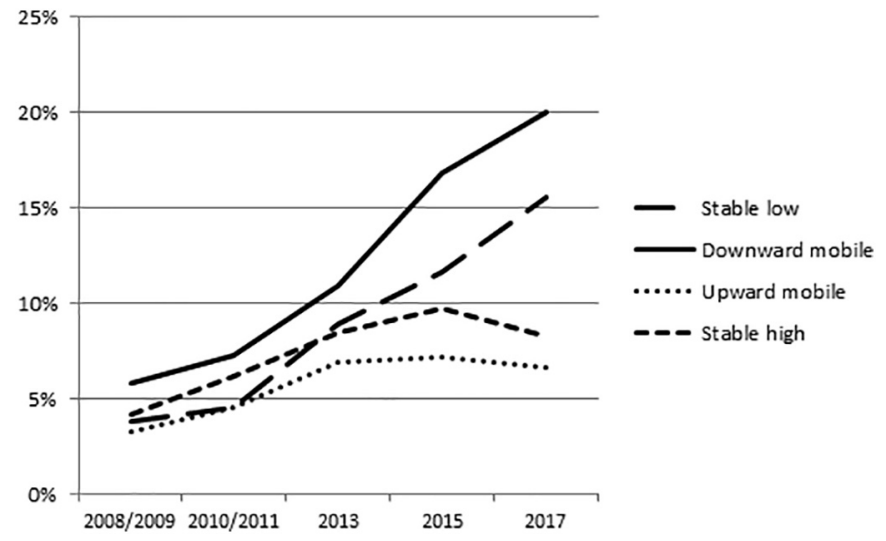

Fig. 2. Daily snus use among boys by intergenerational social mobility, 2008-2017 (\%).

other parental or individual characteristics influencing youth smoking might impact on the availability of cigarettes and reduce the effect of the actual price per se. In future studies, family affluence or SEP should be measured with several indicators (Laaksonen, Rahkonen, Karvonen, \& Lahelma, 2005). The stratified analysis by study year (Supplementary Tables 1, 2 and 3) revealed that the associations between social mobility groups and smoking/snus use differed only a little in different study years. One explanation for the observed significant interaction terms (study year*social mobility, see Tables 2 and 3, model 4) could be the rather large number of observations on the data.

In boys, the association between snus use and social mobility was similar to smoking when all examined demographic variables were taken into account. Earlier studies have shown that SEP and other characteristics may be different for snus users than for smokers (Mattila et al., 2012; Øverland et al., 2010), but the characteristics probably overlap since the concurrent use of these products is common (Tseveenjav et al., 2015). The differences in snus use between academically oriented and non-academically oriented adolescents were not as pronounced as with smoking, however, the differences increased over time. Snus use may contribute to widening inequalities in health if the current trend continues. It is also notable that in 2017 the prevalence of snus use was higher than that of smoking among boys except among the stable low adolescents. This change in tobacco use should be taken into account when designing both preventive and legislative measures. As snus consumption has increased in Finland (National Institute for Health and Welfare, 2018), possible new policy actions should be considered to restrict the availability of snus even more. Probably, no strong opposition would occur as the acceptance of strict tobacco control policy is high in Finland (Ruokolainen et al., 2018). Studying the possible regional differences in both snus use and social mobility within Finland would be an interesting theme for further studies. The price of snus did not affect the association between snus use and SEP. One explanation could be that the price index of snus in Sweden does not correlate to the actual prices at which snus is sold (il)legally in Finland. The price elasticity found in cigarettes is also present in the demand for smokeless tobacco (Jawad, Lee, Glantz, \& Millett, 2018), so price rises could be recommended in order to prevent the increase in snus use.

It is undecided which tobacco control policies help to reduce the socioeconomic differences in smoking among adolescents (Brown, Platt, \& Amos, 2014; Kuipers, Monshouwer, van Laar, \& Kunst, 2015). Price has been shown to be effective in decreasing adolescent smoking (Ross \& Chaloupka, 2003). Several tax increases were enacted during 2008 and 2017 in Finland, raising the nominal price of cigarettes by $63 \%$ (National Institute for Health and Welfare, 2018). In the Netherlands, nationally implemented policies (for example, a ban on the sale of cigarettes to children and national mass media campaigns) decreased smoking among adolescents, but increased the socioeconomic differences in smoking (Kuipers et al., 2014). A quasi-experimental study suggested that the implementation of point-of-sale bans in Europe decreased smoking, caused by the further denormalization of smoking rather than by actually decreasing the accessibility of tobacco (van Hurck, Nuyts, Monshouwer, Kunst, \& Kuipers, 2018). A total ban on tobacco use on all school premises came into force in 2010. Smoking continued to decline and snus use continued to increase after this enactment. It is possible that some of the smokers switched to use snus during this time. However, longitudinal data for answering this question would be needed.The point-of-sale ban was enacted in Finland in 2012. Smoking decreased from the period 2010-2011 to 2013 among adolescents. In terms of the denormalization of smoking, the endgame policy (McDaniel, Smith, \& Malone, 2016) was incorporated in the objective of the Tobacco Act in 2010 and expanded further in 2016. The objective is to end the use of tobacco (and since 2016, also the use of other nicotine-containing products) altogether instead of just restricting it (Finlex, 2016). This will be reached if 5\% or less of population use tobacco or nicotine products daily. It is possible that mass media communication on this strong denormalization policy, together with consecutive tax increases since 2009, may have influenced the declining smoking rates among adolescents (Pekurinen \& Valtonen, 1987).

As Finnish policy aims at both tackling inequalities in health (Melkas, 2013) and ending the use of tobacco products, our results indicate that further actions are needed. As non-academic orientation and low school performance predict smoking (Pennanen, Haukkala, de Vries, \& Vartiainen, 2011), prevention should be targeted more on adolescents with such an orientation and performance. Prevention should include, in addition to cigarettes, also other tobacco products, especially among boys. More strict policy actions, as well as support for stopping snus use, are needed in order to reach the objective of a tobacco-free society.

\subsection{Strengths and limitations}

The strengths of this study are that the School Health Promotion Study is a large nationwide survey and the questions are comparable over the study period. We were able to take into account several demographic factors. The declining coverage rate of the survey in general and the fact that the coverage cannot be estimated for vocational schools need to be taken into account when interpreting the results. A lower educational level predicts both non-responsiveness and smoking (Kopra, Härkänen, Tolonen, \& Karvanen, 2015; Reinikainen, Tolonen, Borodulin, et al., 2018). There are probably more vocational school pupils among the non-respondents, and the socioeconomic differences in tobacco use may be larger than observed in this study. School dropout has been found to predict smoking.(Pedersen \& von Soest, 2017) Those adolescents who leave school after basic education (5\%) were not included in our study population. Education as a proxy for socioeconomic status is not without its challenges (Gagné, Lee, Steinmetz-Wood, \& Frohlich, 2018). As the education of adolescents is still in progress, we can only interpret the social mobility as potential social mobility. Another limitation is that the data is self-reported and students might deny smoking (Patrick et al., 1994). However, the questionnaire was anonymous, which might reduce the possibility of misreporting.

\subsection{Conclusions}

Adolescent smoking and snus use is strongly associated with the educational track, irrespective of the social mobility class and there are vast differences in tobacco use between these groups. During the study period, absolute differences in smoking between social mobility groups declined while relative differences increased. In snus use, both the absolute and the relative differences increased. To fight inequalities in 


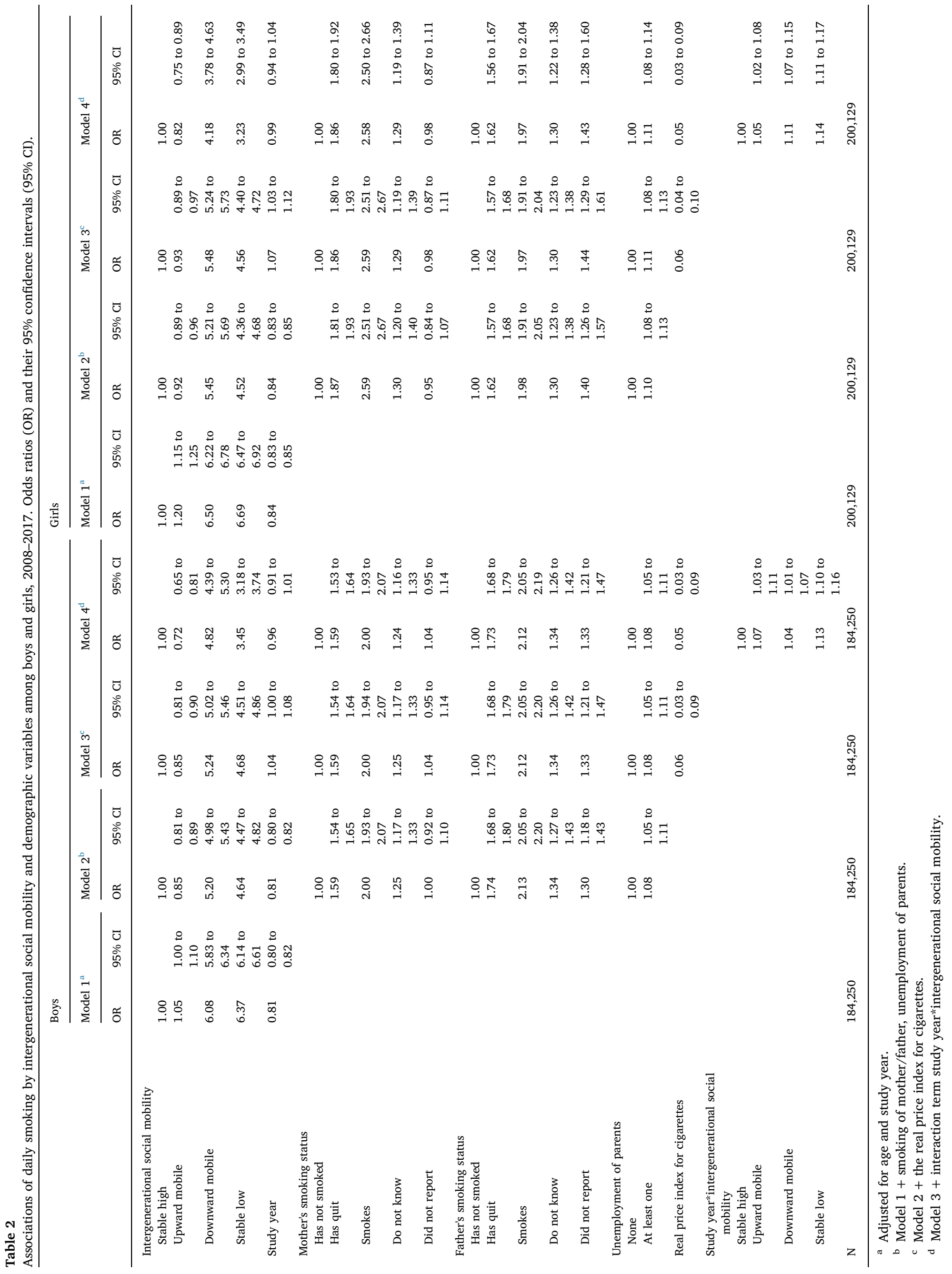


Table 3

Associations of daily snus use by intergenerational social mobility and demographic variables among boys, 2008-2017. Odds ratios (OR) and their $95 \%$ confidence intervals $(95 \% \mathrm{CI})$.

\begin{tabular}{|c|c|c|c|c|c|c|c|c|}
\hline & \multicolumn{2}{|l|}{ Model $1^{\mathrm{a}}$} & \multicolumn{2}{|l|}{ Model $2^{\mathrm{b}}$} & \multicolumn{2}{|l|}{ Model $3^{\mathrm{c}}$} & \multicolumn{2}{|l|}{ Model $4^{\mathrm{d}}$} \\
\hline & OR & $95 \% \mathrm{CI}$ & OR & $95 \% \mathrm{CI}$ & OR & $95 \% \mathrm{CI}$ & OR & $95 \% \mathrm{CI}$ \\
\hline \multicolumn{9}{|c|}{ Intergenerational social mobility } \\
\hline Stable high & 1.00 & & 1.00 & & 1.00 & & 1.00 & \\
\hline Upward mobile & 0.78 & 0.73 to 0.82 & 0.73 & 0.69 to 0.77 & 0.73 & 0.69 to 0.78 & 0.70 & 0.61 to 0.81 \\
\hline Downward mobile & 1.68 & 1.60 to 1.77 & 1.56 & 1.49 to 1.64 & 1.57 & 1.50 to 1.66 & 0.82 & 0.72 to 0.94 \\
\hline Stable low & 1.15 & 1.10 to 1.20 & 1.03 & 0.98 to 1.08 & 1.04 & 1.00 to 1.09 & 0.50 & 0.45 to 0.57 \\
\hline Study year & 1.37 & 1.35 to 1.39 & 1.38 & 1.36 to 1.39 & 1.19 & 1.15 to 1.23 & 1.05 & 1.01 to 1.09 \\
\hline \multicolumn{9}{|l|}{ Mother's smoking status } \\
\hline Has not smoked & & & 1.00 & & 1.00 & & 1.00 & \\
\hline Has quit & & & 1.35 & 1.29 to 1.42 & 1.35 & 1.28 to 1.41 & 1.34 & 1.28 to 1.41 \\
\hline Smokes & & & 1.26 & 1.20 to 1.33 & 1.26 & 1.20 to 1.33 & 1.26 & 1.20 to 1.33 \\
\hline Do not know & & & 1.38 & 1.26 to 1.52 & 1.38 & 1.26 to 1.51 & 1.38 & 1.26 to 1.51 \\
\hline Did not report & & & 1.38 & 1.24 to 1.54 & 1.42 & 1.27 to 1.58 & 1.40 & 1.25 to 1.56 \\
\hline \multicolumn{9}{|l|}{ Father's smoking status } \\
\hline Has not smoked & & & 1.00 & & 1.00 & & 1.00 & \\
\hline Has quit & & & 1.27 & 1.21 to 1.32 & 1.26 & 1.21 to 1.32 & 1.26 & 1.20 to 1.32 \\
\hline Smokes & & & 1.21 & 1.15 to 1.27 & 1.21 & 1.15 to 1.27 & 1.21 & 1.15 to 1.27 \\
\hline Do not know & & & 1.08 & 0.99 to 1.18 & 1.08 & 0.99 to 1.18 & 1.08 & 0.99 to 1.18 \\
\hline Did not report & & & 1.47 & 1.29 to 1.66 & 1.49 & 1.32 to 1.69 & 1.47 & 1.30 to 1.67 \\
\hline \multicolumn{9}{|c|}{ Unemployment of parents } \\
\hline None & & & 1.00 & & 1.00 & & 1.00 & \\
\hline At least one & & & 0.85 & 0.82 to 0.89 & 0.85 & 0.82 to 0.89 & 0.86 & 0.83 to 0.89 \\
\hline Snus price index & & & & & 1.00 & 1.00 to 1.00 & 1.00 & 1.00 to 1.00 \\
\hline \multicolumn{9}{|c|}{ Study year*intergenerational social mobility } \\
\hline Stable high & & & & & & & 1.00 & \\
\hline Upward mobile & & & & & & & 1.01 & 0.96 to 1.05 \\
\hline Downward mobile & & & & & & & 1.22 & 1.17 to 1.26 \\
\hline Stable low & & & & & & & 1.25 & 1.21 to 1.29 \\
\hline $\mathrm{N}$ & 184,250 & & 184,250 & & 184,250 & & 184,250 & \\
\hline
\end{tabular}

a Adjusted for age and study year.

b Model $1+$ smoking of mother/father, unemployment of parents.

c Model $2+$ snus price.

d Model $3+$ interaction term study year*intergenerational social mobility.

health, social mobility within academic and non-academic orientation should be better taken into account in smoking and tobacco use prevention. Actions tackling these inequalities should be carried out already in basic education.

Supplementary data to this article can be found online at https:// doi.org/10.1016/j.addbeh.2019.06.011.

\section{Role of Funding Sources}

O Rahkonen is supported by the Academy of Finland (\#1294514), $\mathrm{JL}$ is supported by the Academy of Finland (\#1294566). The Academy of Finland had no role in the study design, collection, analysis or interpretation of the data, writing the manuscript, or the decision to submit the paper for publication.

\section{Contributors}

O Ruokolainen, HO, JL, and O Rahkonen provided the original idea for the research. All statistical analyses were done by O Ruokolainen. The first draft was prepared by O Ruokolainen, all authors contributed in writing and editing the manuscript. All authors read and approved the final version of the manuscript.

\section{Declaration of Competing Interest}

All authors declare no competing interests.

\section{Acknowledgements}

The authors wish to thank Pauliina Luopa for the data retrieval and offering detailed information on the School Health Promotion Study,
Linda Maripuu for the retrieval of the snus price index and Helena Aavavesi for editing the figures.

\section{References}

Brown, T., Platt, S., \& Amos, A. (2014). Equity impact of interventions and policies to reduce smoking in youth: Systematic review. Tobacco Control, 23(e2), e98-e105. https://doi.org/10.1136/tobaccocontrol-2013-051451.

Doku, D., Koivusilta, L., Rainio, S., \& Rimpelä, A. (2010). Socioeconomic differences in smoking among Finnish adolescents from 1977 to 2007. Journal of Adolescent Health, 47(5), 479-487. https://doi.org/10.1016/j.jadohealth.2010.03.012.

Erikson, R. (2006). Social class assignment and mortality in Sweden. Social Science \& Medicine, 62(9), 2151-2160. https://doi.org/10.1016/j.socscimed.2005.09.009.

Finlex. Tobacco act 549/2016. Translation from Finnish. (2016). https://www.finlex.fi/fi/ laki/kaannokset/2016/en20160549.pdf (Accessed 26 November 2018).

Gagné, T., Lee, J. G. L., Steinmetz-Wood, M., \& Frohlich, K. L. (2018). Methodological systematic review of studies on social inequalities in smoking among young adults: A field coming of age? Tobacco Control. https://doi.org/10.1136/tobaccocontrol-2018054576 Published Online First 5 November 2018.

Hagquist, C. E. (2007). Health inequalities among adolescents-the impact of academic orientation and parents' education. European Journal of Public Health, 17(1), 21-26. https://doi.org/10.1093/eurpub/ckl087.

Hoebel, J., Kuntz, B., Kroll, L. E., et al. (2018). Trends in absolute and relative educational inequalities in adult smoking since the early 2000s: The case of Germany. Nicotine \& Tobacco Research, 20(3), 295-302. https://doi.org/10.1093/ntr/ntx087.

Homma, Y., Saewyc, E., \& Zumbo, B. D. (2016). Is it getting better? An analytical method to test trends in health disparities, with tobacco use among sexual minority vs. heterosexual youth as an example. International Journal for Equity in Health, 15, 79. https://doi.org/10.1186/s12939-016-0371-3.

van Hurck, M. M., Nuyts, P. A. W., Monshouwer, K., Kunst, A. E., \& Kuipers, M. A. G. (2018). Impact of removing point-of-sale tobacco displays on smoking behaviour among adolescents in Europe: A quasi-experimental study. Tobacco Control. https:// doi.org/10.1136/tobaccocontrol-2018-054271 Published Online First 20 July 2018.

Jawad, M., Lee, J. T., Glantz, S., \& Millett, C. (2018). Price elasticity of demand of noncigarette tobacco products: A systematic review and meta-analysis. Tobacco Control, 27(6), 689-695. https://doi.org/10.1136/tobaccocontrol-2017-054056.

Karvonen, S., Rimpelä, A. H., \& Rimpelä, M. K. (1999). Social mobility and health related behaviours in young people. Journal of Epidemiology and Community Health, 53(4), 
211-217.

Kopra, J., Härkänen, T., Tolonen, H., \& Karvanen, J. (2015). Correcting for non-ignorable missingness in smoking trends. Stat, 4(1), 1-14. https://doi.org/10.1002/sta4.73.

Kuipers, M. A. G., Monshouwer, K., van Laar, M., \& Kunst, A. E. (2015). Tobacco control and socioeconomic inequalities in adolescent smoking in Europe. American Journal of Preventive Medicine, 49(5), e64-e72. https://doi.org/10.1016/j.amepre.2015.04.032.

Kuipers, M. A. G., Nagelhout, G. E., Willemsen, M. C., \& Kunst, A. E. (2014). Widening educational inequalities in adolescent smoking following national tobacco control policies in the Netherlands in 2003: A time-series analysis. Addiction, 109(10), 1750-1759. https://doi.org/10.1111/add.12637.

Kuntz, B., \& Lampert, T. (2013). Educational differences in smoking among adolescents in Germany: What is the role of parental and adolescent education levels and intergenerational educational mobility? International Journal of Environmental Research and Public Health, 10(7), 3015-3032. https://doi.org/10.3390/ijerph10073015.

Laaksonen, M., Rahkonen, O., Karvonen, S., \& Lahelma, E. (2005). Socioeconomic status and smoking. Analysing inequalities with multiple indicators. European Journal of Public Health, 15(3), 262-269. https://doi.org/10.1093/eurpub/cki115.

de Looze, M., ter Bogt, T., Hublet, A., et al. (2013). Trends in educational differences in adolescent daily smoking across Europe, 2002-10. European Journal of Public Health, 23(5), 846-852. https://doi.org/10.1093/eurpub/ckt022.

Mattila, V. M., Raisamo, S., Pihlajamäki, H., Mantysaari, M., \& Rimpelä, A. (2012). Sports activity and the use of cigarettes and snus among young males in Finland in 1999-2010. BMC Public Health, 12, 230. https://doi.org/10.1186/1471-2458-12 230.

McDaniel, P. A., Smith, E. A., \& Malone, R. E. (2016). The tobacco endgame: A qualitative review and synthesis. Tobacco Control, 25(5), 594-604. https://doi.org/10.1136/ tobaccocontrol-2015-052356.

Melkas, T. (2013). Health in all policies as a priority in Finnish health policy: A case study on national health policy development. Scandinavian Journal of Public Health, 41(Suppl. 11), 3-28. https://doi.org/10.1177/1403494812472296.

National Institute for Health and Welfare (2018). Tobacco statistics 2017. Statistical report 37/2018. Official statistics of Finland. Helsinki, Finland: National Institute for Health and Welfarehttp://urn.fi/URN:NBN:fi-fe2014101445179 (Accessed 26 November 2018).

Novak, M., Ahlgren, C., \& Hammarstrom, A. (2012). Social and health-related correlates of intergenerational and intragenerational social mobility among Swedish men and women. Public Health, 126(4), 349-357. https://doi.org/10.1016/j.puhe.2012.01. 012 .

Øverland, S., Tjora, T., Hetland, J., \& Aarø, L. E. (2010). Associations between adolescent socioeducational status and use of snus and smoking. Tobacco Control, 19(4), 291-296. https://doi.org/10.1136/tc.2009.034512.

Paavola, M., Vartiainen, E., \& Haukkala, A. (2004). Smoking from adolescence to adulthood - The effects of parental and own socioeconomic status. European Journal of Public Health, 14(4), 417-421. https://doi.org/10.1093/eurpub/14.4.417.
Patrick, D. L., Cheadle, A., Thompson, D. C., Diehr, P., Koepsell, T., \& Kinne, S. (1994). The validity of self-reported smoking: A review and meta-analysis. American Journal of Public Health, 84(7), 1086-1093.

Pedersen, W., \& von Soest, T. V. (2017). How is low parental socioeconomic status associated with future smoking and nicotine dependence in offspring? A populationbased longitudinal 13-year follow-up. Scandinavian Journal of Public Health, 45(1), 16-24. https://doi.org/10.1177/1403494816680800.

Pekurinen, M., \& Valtonen, H. (1987). Price, policy and consumption of tobacco: The Finnish experience. Social Science \& Medicine, 25(8), 875-881.

Pennanen, M., Haukkala, A., de Vries, H., \& Vartiainen, E. (2011). Longitudinal study of relations between school achievement and smoking behavior among secondary school students in Finland: Results of the ESFA study. Substance Use \& Misuse, 46(5), 569-579. https://doi.org/10.3109/10826084.2010.517725.

Rainio, S. U., Rimpelä, A. H., Luukkaala, T. H., \& Rimpelä, M. K. (2008). Evolution of the association between parental and child smoking in Finland between 1977 and 2005. Preventive Medicine, 46(6), 565-571. https://doi.org/10.1016/j.ypmed.2008.01.011.

Reinikainen, J., Tolonen, H., Borodulin, K., et al. (2018). Participation rates by educational levels have diverged during 25 years in Finnish health examination surveys. European Journal of Public Health, 28(2), 237-243. https://doi.org/10.1093/eurpub/ ckx151.

Ross, H., \& Chaloupka, F. J. (2003). The effect of cigarette prices on youth smoking. Health Economics, 12(3), 217-230. https://doi.org/10.1002/hec.709.

Ruokolainen, O., Heloma, A., Jousilahti, P., et al. (2019). Thirty-eight year trends of educational differences in smoking in Finland. International Journal of Public Health. https://doi.org/10.1007/s00038-019-01228-x in press.

Ruokolainen, O., Ollila, H., Patja, K., Borodulin, K., Laatikainen, T., \& Korhonen, T. (2018). Social climate on tobacco control in an advanced tobacco control country: A population-based study in Finland. Nordic Studies on Alcohol and Drugs, 35(3), 152-164. https://doi.org/10.1177/1455072518767750.

Statistics Finland (Statistics Finland's PX-Web databases). Immediate transition to further studies by those having ended 9th grade of comprehensive school by location area of comprehensive school in 2000-2016. (2017). http://pxnet2.stat.fi/PXWeb/pxweb/en/ StatFin/StatFin_kou_khak/statfin_khak_pxt_001.px/?rxid=18a5cad1-7ce5-4cfca54d-7cec91a2c495 (Accessed 26 November 2018).

Tseveenjav, B., Pesonen, P., \& Virtanen, J. I. (2015). Use of snus, its association with smoking and alcohol consumption, and related attitudes among adolescents: The Finnish National School Health Promotion Study. Tobacco Induced Diseases, 13, 34. https://doi.org/10.1186/s12971-015-0058-3.

Vipunen. Education Statistics Finland. Aiempi ja myöhempi koulutus [Prior and later degrees]. (2018). https://vipunen.fi/fi-fi/yliopisto/Sivut/Aiempi-ja-my\%C3\%B6hempikoulutus.aspx (Accessed 1 March 2019).

Vuolo, M., \& Staff, J (2013). Parent and child cigarette use: A longitudinal, multigenerational study. Pediatrics, 132, e568. https://doi.org/10.1542/peds.2013-0067. 